\title{
The Detection of Illicit Cryptocurrency Mining Farms in Electrical Distribution Systems with Innovative Approaches
}

\author{
Istanbul Technical University \\ gulomer@itu.edu.tr
}

\begin{abstract}
-Since the most important constituent of the cost of cryptocurrency production is energy bills, use of illegal electricity in cryptocurrency mining farms is very common. For this reason, many countries prohibit cryptocurrency production or restrict it with some legal regulations. This situation raises the problem of how to detect illicit cryptocurrency mining. Therefore, innovative approaches are needed to detect illicit cryptocurrency mining farms. In this study, it has been shown that unique noise and/or harmonic characteristics of machines producing cryptocurrency can be used to detect illicit cryptocurrency mining farms. The unique harmonic characteristics formed by data centers on neutral line have been detected by field measurements performed. Electricity distribution companies can make risk assessments with this approach by monitoring energy quality data. As a result, the necessary legal permissions can be obtained to investigate suspicious high-risk consumers. Illicit cryptocurrency mining farms can be detected by investigating at highrisk consumer facilities.
\end{abstract}

Key Words: Cryptocurrency; Electricity theft; Energy consumption; $\mathrm{CO} 2$ emission; power signatures.

\section{Introduction}

The increase in various issues like economic problems emerging after the global economic crisis in 2008, trade embargoes becoming widespread among countries across the world, the troubles in the banking system and the economic attacks of strong currencies against developing countries have increased the search for new solutions to overcome these problems. Cryptocurrencies produced as an alternative to assets monetized by central government's first emerged in 2008. The use of cryptocurrencies is becoming increasingly widespread due to the fact that they can find solutions to at least some of the economic problems mentioned above and they can provide various benefits [1][2]. The process of producing and using cryptocurrencies cannot be fully traced by states because they are decentralized. Therefore, the use of cryptocurrency causes a number of security problems.

It is possible to earn income from cryptocurrencies by means of crypto mining. Crypto mining is the process of producing cryptocurrency with a computer system [3][4]. In order to earn income from crypto mining, as in the case of every economic investment, the investment and operating costs must be lower than the income. The two most basic parameters related to the cost in crypto mining are the computer hardware and electrical energy cost required for the installation and operation of the system [5]. The costs for information technology products are almost the same all over the world. Therefore, the unit cost of electrical energy is the most important factor that determines the income obtained from cryptocurrency production. Worldwide, the energy spent on cryptocurrency production has surpassed that spent by many countries. It is expected that the energy to be used for cryptocurrency production will gradually increase [6]. Because the majority of electrical energy is derived from fossil sources, it results in increased $\mathrm{CO} 2$ emissions. Considering the global warming problem facing the world, the amount of electricity consumed by cryptocurrency production increases concerns about a livable environment [7]. In addition, the use of illegal electricity is often seen to earn high income from cryptocurrency production. Cryptocurrency production is expected to spread rapidly in regions where electricity consumption is still high due to weak central authority or insufficient controls.

There is a consensus among many countries to decrease $\mathrm{CO} 2$ emissions. In order to reduce the increasing $\mathrm{CO} 2$ emissions, the production of cryptocurrency must be limited. Considering the increased number of cryptocurrencies and their market value, there is a need to develop various methods for the detection of illicit cryptocurrency mining farms to reduce the use of illegal electricity. 
Because of this, identifying illicit cryptocurrency production centers has become an important research topic in recent years.

Electricity distribution companies have started using new methods to detect illegal electricity consumption in addition to traditional methods [7]. These traditional methods used by electricity distribution companies are inadequate to detect cryptocurrency mining farms, because the regions where illicit cryptocurrency production is mostly carried out have high loss/leakage electricity rates. Therefore, innovative methods are necessary to identify illicit cryptocurrency production centers.

In this study, an innovative approach is explained to detect the locations of illicit cryptocurrency farms. This innovative approach uses unique electrical characteristics, such as current harmonics and the electrical noise of switched power supplies used by the equipment employed in cryptocurrency production. It has been shown with this new approach that the facilities related to illicit production can be detected with high accuracy compared to traditional methods instructions.

The rest of the paper is organized as follows: Section 2 explains the background of the cryptocurrencies. Also, Section 3 describes the detection of illicit cryptocurrency mining. The case study is given in Section 4 and the conclusions are given in section 5 .

\section{Cryptocurrencies}

In this section, cryptocurrencies will be explained on the basis of Bitcoin, because Bitcoin is in widespread use and has the greatest market value. In 2008, the world was first introduced to a cryptocurrency called Bitcoin by an article published by a hacker (or hackers) called Satoshi Nakamoto [8]. This cryptocurrency has increased its popularity since its release to the market in January 2009. Nakamoto defined Bitcoin as a decentralized and peer-to-peer (P2P) system that connects money holders directly, without any server or centralized authority [9].

Today there are more than 130 cryptocurrencies with a market value of more than $\$ 100$ million [10]. Many cryptocurrencies emerged after Bitcoin, all collectively termed Altcoin [11]. Ethereum (ETH), Ripple (XRP), Stellar (XLM) and EOS are the main Altcoins.

Cryptocurrencies are used by many people because of their various benefits. The main benefits of cryptocurrencies for users include the fact that [12]:

- They cannot be monitored by a central authority because they are designed for confidentiality

- They cannot be taxed because they cannot be followed by governments

- Money transfers and the amounts of money belonging to users cannot be known by any other users except themselves

- They reduce the security risk because they are not physically handled.

In addition to all the advantages provided by cryptocurrencies, there are significant social disadvantages as well. Because cryptocurrencies cannot be followed by a central authority, it is estimated that these currencies are widely used in illegal activities.

Bitcoin has been the most important among all the emerging cryptocurrencies. The reason for this is that Bitcoin promises to be a currency unit independent from a central government and aims to operate all of its production and approval processes independently from central government [2]. Bitcoin has grown rapidly since its release to the market in January 2009 and its total market value has exceeded $\$ 110$ billion at 2018 [13]. Figure 1 shows the change of the market capitalization of a Bitcoin by years.

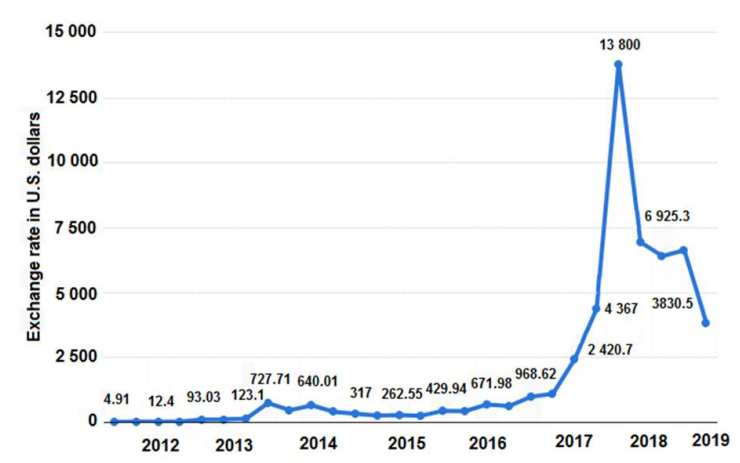

Fig. 1. Change in the market capitalization of a Bitcoin by years [14]

Daily Bitcoin revenue is up to $\$ 8$ million [15]. It is not only the market value of Bitcoin but also the market values of alternative cryptocurrencies collectively called Altcoin that are increasing day by day. As of April 2019, there were 15 cryptocurrencies 
with a market value of over $\$ 1$ billion. Table 1 shows 15 cryptocurrencies with a market value more than $\$ 1$ billion.

Table I. Cryptocurrencies with a market capitalization of more than $\$ 1$ billion [13]

\begin{tabular}{llll}
\hline $\begin{array}{l}\text { Name of } \\
\text { Cryptocurre } \\
\text { ncy }\end{array}$ & $\begin{array}{l}\text { Market } \\
\text { Capitalization } \\
(\$)\end{array}$ & $\begin{array}{l}\text { Name of } \\
\text { Cryptocurre } \\
\text { ncy }\end{array}$ & $\begin{array}{l}\text { Market } \\
\text { Capitalization }(\$)\end{array}$ \\
\hline Bitcoin & 90.741 .538 .895 & Cardano & 2.318 .592 .794 \\
Ethereum & 17.672 .99 .803 & Tether & 2.086 .116 .793 \\
XRP & 14.934 .920 .870 & TRON & 1.883 .525 .345 \\
Bitcoin & 5.616 .072 .533 & Bitcoin SV & 1.501 .343 .519 \\
Cash & & & \\
Litecoin & 5.606 .043 .136 & Monero & 1.161 .573 .585 \\
EOS & 4.890 .378 .036 & Dash & 1.158 .308 .400 \\
Binance & 2.684 .300 .981 & IOTA & 1.006 .277 .557 \\
Coin & & & \\
Stellar & 2.450 .560 .103 & & \\
\hline
\end{tabular}

Nowadays, many users carry out cryptocurrency mining to obtain revenue from the cryptocurrency industry, which has a high market value

\subsection{The Electrical Energy Consumption of Bitcoin Mining}

In the early days of Bitcoin production, Bitcoin mining could be performed with standard computers due to its low level of difficulty [5]. The need for a large number of powerful computer systems now required for Bitcoin mining has increased the energy required for mining. Figure 2 shows the amount of energy required to produce a Bitcoin in the United States with respect to various equipment.

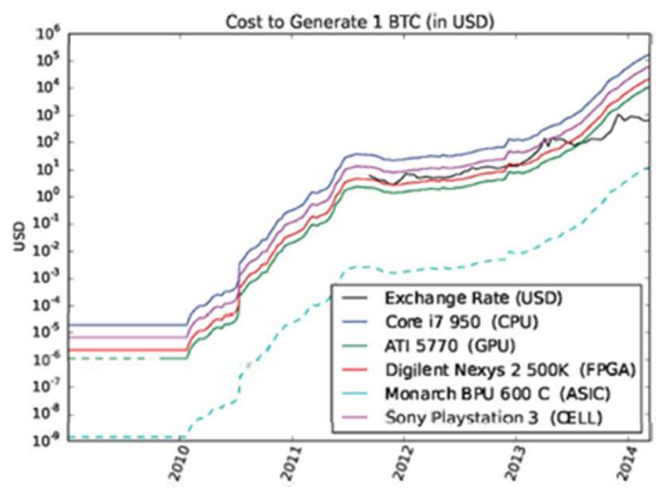

Fig. 2. The amount of energy consumption required for mining one Bitcoin in the U.S. [16].

Although less energy consuming technologies have been developed for cryptocurrency production, the energy required for cryptocurrency production has gradually increased day by day because
Bitcoin production has constantly become more difficult. The energy required for the production of a Bitcoin is almost equal to the one-week energy demand of a house [17]. Numerous studies have been conducted to determine the total energy spent on Bitcoin production worldwide. A study performed in Ireland has shown that the energy spent on Bitcoin can compete with the total consumption of Ireland [16]. In another study, the energy used for Bitcoin production was compared with the total energy consumption of countries. Figure 3 shows the total energy consumption of Bitcoin production compared to the total energy consumption of various countries.

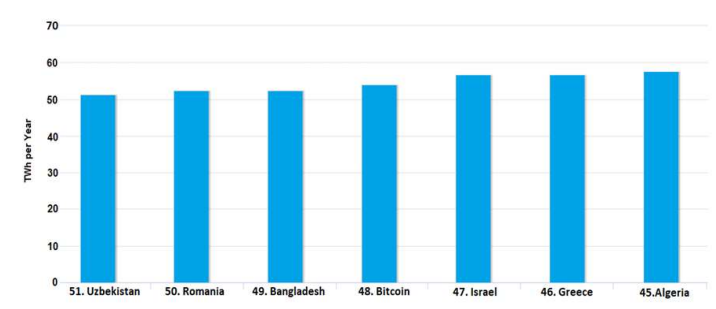

Fig. 3. Comparison of energy consumed for Bitcoin production versus countries [6]

The energy spent for Bitcoin production is ranked 48th among the countries of the world, surpassing 150 countries. This indicates how high the energy requirement spent on Bitcoin production is. The increased use of cryptocurrencies increases environmental concerns because high energy consumption causes high $\mathrm{CO} 2$ emissions, resulting in environmental effects [7].

One of the most significant costs of Bitcoin production is the electrical energy cost. For this reason, in order to obtain a high income from Bitcoin production, the energy unit price should be low. Some Bitcoin manufacturers prefer a more efficient mining pool system rather than individual production, because they cannot afford the energy unit costs [18]. Moreover, the data centers where Bitcoin is produced have to be cooled to work efficiently, and the energy required to cool data centers is also quite high [19][20]. Therefore, regions having cold climatic conditions and low energy unit prices are ideal for Bitcoin production. Bitcoin production performed in the regions where climate conditions are hot and energy 
unit prices are high, suggests the possibility of illegal use of electricity. Table 2 shows the costs required for Bitcoin production, considering average electricity prices.

Table 2. The cost to mine 1 Bitcoin based on the average electricity cost per country [21]

\begin{tabular}{llll}
\hline Country & Price $(\$)$ & Country & Price $(\$)$ \\
\hline China & 3,172 & Turkey & 4,984 \\
Georgia & 3,316 & UK & 8,402 \\
Canada & 3,965 & Italy & 10,310 \\
Russia & 4,675 & Germany & 14,275 \\
USA & 4,758 & S. Korea & 26,170 \\
\hline
\end{tabular}

Energy costs are set to zero if the energy required for cryptocurrency production is provided free of by illegal means. Cryptocurrency production is expected to be common in countries where illegal electricity use is widespread.

Production facilities are established in regions close to hydroelectric dams where the energy unit price is low. However, no matter how low the energy unit price is, it is not possible for the producers to compete with those using electricity illegally. For example, the KnCminer Company, which was supplied cheap electricity from a local hydroelectric power plant in Sweden, went bankrupt in 2016 because it could not afford the high costs [5]. It is clearly observed that the unit price of electric energy is of vital importance for cryptocurrency production.

\subsection{CO2 Emissions from Cryptocurrency Mining}

Cryptocurrency production generates significant $\mathrm{CO} 2$ emissions due to high electrical energy consumption. Each successful Bitcoin produced releases approximately $356.86 \mathrm{~kg}$ of $\mathrm{CO} 2$ gas. The amount of $\mathrm{CO} 2$ released per year for Bitcoin production is calculated to be $35,830 \mathrm{kT} \mathrm{[6].}$ There are few comprehensive studies on the energy consumption and $\mathrm{CO} 2$ emissions of other cryptocurrencies collectively termed Altcoin. However, J. Li et al. studied the CO2 emission of the cryptocurrency called Monero and revealed that this Altcoin also produced high $\mathrm{CO} 2$ emissions [22]. It is also estimated that other Altcoins cause high energy consumption and $\mathrm{CO} 2$ emissions similar to Bitcoin. Considering that only
Bitcoin's energy consumption is more than many countries, it is clear that cryptocurrencies' total $\mathrm{CO} 2$ emissions are quite high. In addition, the dynamic relationship between energy consumption and its $\mathrm{CO} 2$ emissions are clearly observed in the studies that examining the $\mathrm{CO} 2$ emissions of various countries [23] [24].

By means of the Paris agreement and the Kyoto Protocol, governments have signed agreements to reduce $\mathrm{CO} 2$ emissions and committed to take various measures for its reduction [25] [26]. Comprehensive cooperation between countries is necessary to decrease $\mathrm{CO} 2$ emissions caused by cryptocurrency production.

\section{The Detection of Illicit Cryptocurrency Mining}

Illegal electricity is often used to increase income obtained from cryptocurrency production. A Bitcoin manufacturer in China generated $150 \mathrm{MWh}$ of illegal electricity in a production facility built using 200 computers [27]. In the Netherlands, electricity trafficking observed on farms has increased by $20 \%$ in the last five years. In another case that occurred in the Netherlands, a company manager was fired because he set up a secret mining system in the company's server room [28]. In Russia, a number of scientists were arrested who were found to have used Bitcoin mining on the servers of a confidential facility producing nuclear warheads [29]. Bitcoin miners in Turkey perform Bitcoin production with the illegal electricity obtained from irrigation facilities established by the central government for irrigation of farmlands. In addition, they use the financial support received from the government for the purpose of agriculture or animal husbandry to produce illegal Bitcoins [30].

Worldwide, approximately $\$ 90$ billion of illegal electricity is used annually [28]. The high level of electricity trafficking increases the risk of illegal cryptocurrency mining worldwide. Cryptocurrency production should be restricted to prevent the environmental problems caused by it. For all these reasons, the detection of illegal cryptocurrency production has become quite important. 


\subsection{Traditional Methods Used}

In the countries where cryptocurrency production is prohibited or subject to legal regulations, how to detect illegal production poses a serious problem. Nowadays, electricity distribution companies use various methods to uncover illegal cryptocurrency production facilities.

The most common of these methods is that the electricity consumption characteristics of consumers are collected depending on their activities and compared to those of their counterparts. If the energy consumption is much higher than the normal value, this situation is considered suspicious and the consumer facilities are examined. To combat this method, illegal cryptocurrency producers use high electrical energy consuming areas for production, i.e. old factory buildings, to make their detection much harder. The risk of illegal cryptocurrency production is very high in areas with high loss/leakage electricity rates. In another method, the amount of energy distributed by electricity distribution companies to a certain region is compared with existing measured and recorded energy consumptions and a significant increase in unrecorded consumption is considered to be suspicious. A detailed analysis can then be carried out to determine whether illegal cryptocurrency production is occurring.

However, new equipment installed to monitor the network and collect data is physically destroyed or electrically deactivated by people using electricity illegally. Thus, the use of illegal electricity continues in these regions. For example, in the region supplied by Dicle Electricity Distribution Inc., which has the highest loss/leakage electricity rate (64\%) in Turkey, $\$ 5$ million was spent installing equipment to decrease loss/leakage electricity, but it was all destroyed [31].

Another method called the game theorybased detection technique is used in regions where consumer consumption cannot be monitored [32]. In this method, as in the previous one, it is necessary to integrate equipment to be used for network measurements. In the regions where the use of illegal electricity is widespread, it is unable to integrate new equipment without the equipment being destroyed.

Private property must be entered to determine illegal cryptocurrency production in a facility. In many countries, legal searches in private properties can be made if there is strong evidence.

All these problems in identifying and preventing illegal production indicate that innovative solutions are needed. In this respect, the use of current harmonics and electrical noise characteristics in smart energy meters, which are the unique electrical properties of computer systems used for production, will enable the detection of illegal production facilities with higher accuracy. Once legal permission is obtained regarding the consumer, it can be determined from detailed inspections in facilities whether illegal cryptocurrency is produced and illegal electricity is being used.

\subsection{Detection Approach Using Characteristic Electrical Equipment Noise}

Each device that consumes electrical energy has its own specific electrical noise characteristics. For example, dishwashers and drills cause aperiodic impulsive noise due to on-off switching transients, while Switched Mode Power Supplies (SMPS) cause periodic impulsive noise asynchronously to the mains alternating current (AC) cycles.

Güzelgöz et al. investigated the impulsive noise characteristics of various electrical devices in the range from $30 \mathrm{kHz}$ to $50 \mathrm{MHz}$ [33]. It was shown in that study that the noise characteristics of each electrical device were different in terms of both time and frequency. Table 3 shows the noise characteristics of various electrical devices.

Moreover, the noise characteristics obtained in this study were characterized by power spectral density (PSD). 
Table 3. Noise Characteristics of Various Electrical Devices [33]

\begin{tabular}{|c|c|c|}
\hline Measured Device & Frequency & Time \\
\hline Computer tower & $\begin{array}{l}\text { A noticeable rise over } \\
\text { the background noise } \\
\text { as high as } 55 \mathrm{~dB} \text { for the } \\
\text { measurement } \\
\text { frequency range with } \\
\text { most of the power } \\
\text { contained up to } 4 \mathrm{MHz}\end{array}$ & $\begin{array}{l}\text { Raised up by } \\
45 \mathrm{~dB} \text { above the } \\
\text { background } \\
\text { noise level for } \\
\text { most of the AC } \\
\text { cycle duration }\end{array}$ \\
\hline Dimmer & $\begin{array}{l}\text { A noticeable rise over } \\
\text { the background noise } \\
\text { as high as } 35 \mathrm{~dB} \text { for the } \\
\text { measured frequency } \\
\text { range with most of the } \\
\text { power contained up to } \\
5 \mathrm{MHz}\end{array}$ & $\begin{array}{l}\text { Raised up by } \\
\text { 40dB above the } \\
\text { background } \\
\text { noise for a very } \\
\text { short time over } \\
\text { the AC cycle } \\
\text { duration }\end{array}$ \\
\hline LCD monitor & $\begin{array}{l}\text { A noticeable rise over } \\
\text { the background noise } \\
\text { up to } 20 \mathrm{~dB} \text { for the } \\
\text { measured frequency } \\
\text { range with most of the } \\
\text { power distributed over } \\
\text { a broader range of } \\
\text { frequencies with } \\
\text { prominent spikes at } \\
\text { some particular } \\
\text { frequencies }\end{array}$ & $\begin{array}{l}\text { Raised up by } \\
13 \mathrm{~dB} \text { above the } \\
\text { background } \\
\text { noise level } \\
\text { covering most } \\
\text { of the AC cycle } \\
\text { duration }\end{array}$ \\
\hline Fluorescent & $\begin{array}{l}\text { A noticeable rise over } \\
\text { the background noise } \\
\text { up to } 10 \mathrm{~dB} \text { for the } \\
\text { measured frequency } \\
\text { range with most of the } \\
\text { power concentrated } \\
\text { around } 5 \mathrm{MHz}\end{array}$ & $\begin{array}{l}\text { Raised up by } \\
6 \mathrm{~dB} \text { above the } \\
\text { background } \\
\text { noise level } \\
\text { covering half of } \\
\text { the AC cycle } \\
\text { duration }\end{array}$ \\
\hline Laptop charger & $\begin{array}{l}\text { A noticeable rise over } \\
\text { the background noise } \\
\text { as high as } 15 \mathrm{~dB} \text { for the } \\
\text { measured frequency } \\
\text { range with most of the } \\
\text { power contained up to } \\
25 \mathrm{MHz}\end{array}$ & $\begin{array}{l}\text { Raised up by } \\
13 \mathrm{~dB} \text { above the } \\
\text { background } \\
\text { noise level } \\
\text { covering half of } \\
\text { the AC cycle } \\
\text { duration }\end{array}$ \\
\hline
\end{tabular}

Figure 4 shows noise characteristics for a computer tower and LCD monitor.
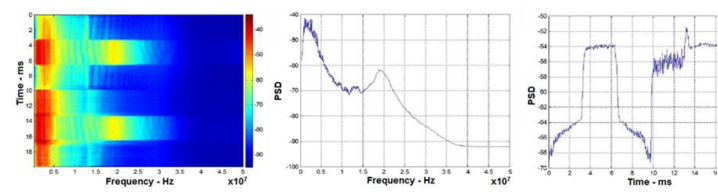

(a)
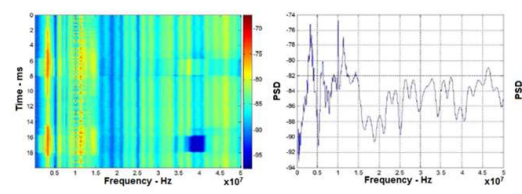

(b)

Fig. 4. (a) Computer tower (b), LCD monitor noise characteristics [33]

Electricity distribution companies can determine the identity of the devices operating in the measurement area by using the devices' specific noise characteristics. In the light of this information, success in identifying illegal cryptocurrency production facilities with different characteristics can be increased.

\subsection{Detection Approach with Using the Harmonic Characteristics of Equipment}

Each nonlinear element draws harmonic currents from the network in different amounts depending on its electrical characteristics. Accordingly, if the harmonic spectrum of an electrical system is obtained, the devices inside that system can be detected. Cryptocurrency production is carried out by a number of high-powered computers, and the electricity consumption of other constituents in the facilities where mining is performed is negligible compared to these computers. Switched mode power supplies (SMPS) are used to supply computers. Switched mode power supplies draw harmonic current from the electrical network [34].

Figure 5 shows the supply voltage, nonsinusoidal current waveform and harmonic current spectrum of switched mode power supplies used in computers.

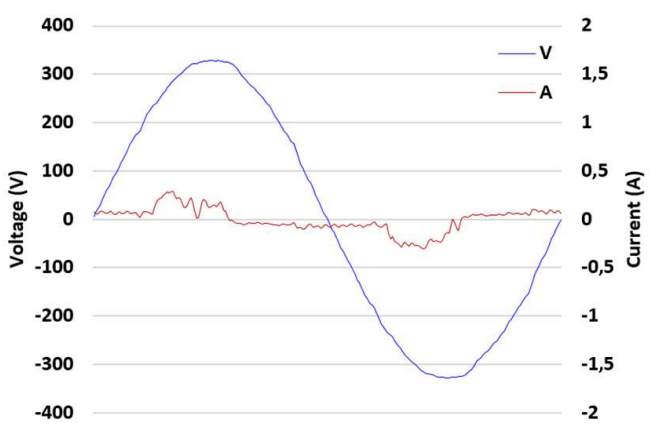

(a)

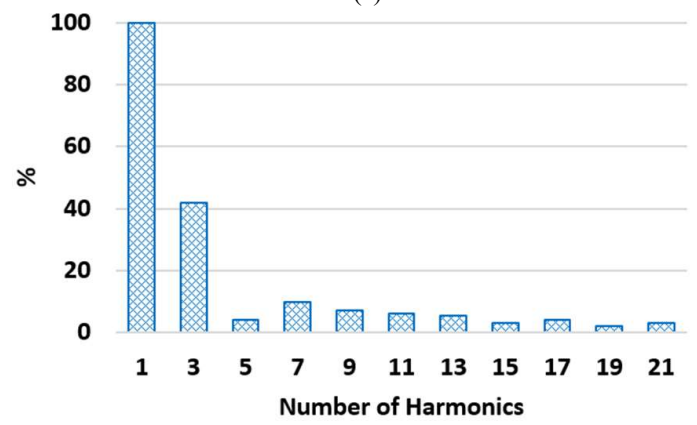

(b)

Fig.5. (a) Supply voltage, current waveform, (b) current harmonic spectrum of a computer manufactured in 2018 
The passive or active Power Factor Correction (PFC) circuits used in switched mode power supplies circuits draw currents very close to the sinusoidal form by correcting the waveform of the current it draws from the network. In published literature, there are many studies that design the PFC circuit to correct the power factors of the waveforms of SMPS-containing devices [35][36]. However, PFC circuits are not commonly used in computer switched mode power supplies. The reason for this is that PFC circuits increase the cost of switched mode power supplies and the increased cost decreases the competitiveness of PFC circuits. Furthermore, Electromagnetic Compatibility standards that regulate harmonics such as IEEE 519 and the Canadian Standards Association (CSA) 61000-3-6 limit the harmonics by taking into account the entire system instead of a single element [37] [38]. Only the IEC 61000-3-2 standard includes a regulation for limiting the harmonic value of a single device [39]. When the datasheets of cutting-edge technology switched mode power supplies are examined, it is observed that some of them do not have a PFC circuit and many of the models containing PFC circuits do not comply with the IEC 61000-3-2 standard, which limits the harmonics for single components.

Figure 6 shows the current harmonic spectra of single-phase switched mode power supplies of three different brands of computers manufactured in 2010, 2013 and 2018.

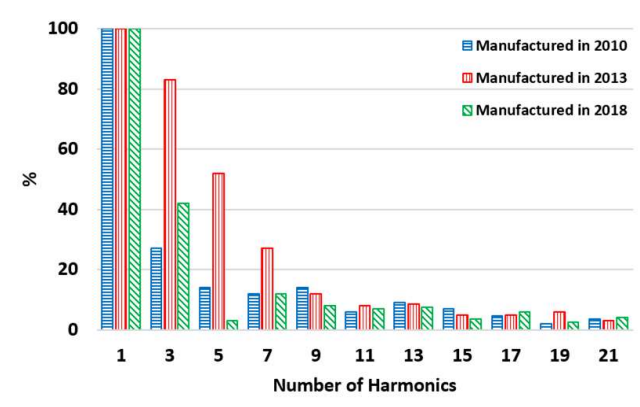

Fig. 6. Current harmonic spectra of singlephase switched mode power supplies of three different brands of computers manufactured in 2010, 2013 and 2018

Figure 6 shows that due to the reasons explained above, computers have continued to draw high harmonic currents as in the past. Due to the fact that numerous computers producing high harmonic currents are combined for the production of cryptocurrencies, cryptocurrency production facilities can be easily monitored on the distribution network via harmonic currents.

There are a large number of electrical devices in the electricity network that draws harmonic current. Therefore, every harmonic detected in the network does not indicate that there is a cryptocurrency facility in that region. In order to detect a cryptocurrency facility over the network, the harmonic current drawn by this facility must be characterized.

Each device that draws harmonic current has different harmonic spectra. Figure 7 shows the harmonic spectra of various electrical devices.
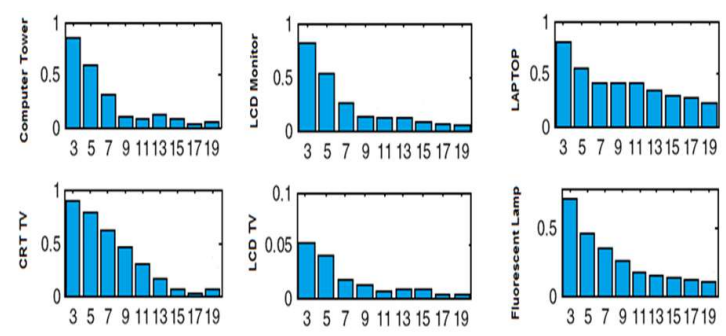

Fig. 7. Harmonic spectra of various electrical devices [40]

Examining Figure 7, it is seen that each non-linear device has a different harmonic spectrum. However, there is not a significant feature that distinguishes computers from the other devices.

Many powerful computers operate at the same time in cryptocurrency production facilities. Therefore, it should be determined how the increasing number of elements, the increasing power consumed and the powerdependent loading affects the harmonics.

In three-phase, four-wire, low-voltage distribution systems - supplied by linear electrical loads - evenly distributed loads mean that there is no current flow over the neutral line. If the linear loads are not distributed evenly between the three phases, current flows because of the resulting imbalance in the neutral line. Because the loads supplied from the low voltage 
distribution network are linear, the current flowing through the neutral line only has a basic component. Even if the loads are perfectly balanced in the three-phase, fourwire systems with non-linear loads - such as switched mode power supplies, electronic ballast and uninterruptible power supplies (UPS) - the loads cause currents flowing on the neutral line due to their harmonic currents. Some of the harmonic current components attenuate each other and some of them are cancelled out completely. The third order harmonic currents increase in the neutral conductor. The harmonic characteristics of systems such as data centers and cryptocurrency production centers, which are formed by combining many computers side-by-side, can be obtained by examining the decreasing and increasing effects in the harmonic components.

The most distinctive characteristic of the computer's electrical current occurs in the neutral line due to third order harmonics (third, sixth, ninth, etc.). In three-phase systems, the third order harmonics do not cancel each other out but occur in the neutral because it is the common return. When the harmonic spectrum of the neutral current is examined, the third order neutral conductor harmonics are much higher than the phase conductors. In the facilities performing cryptocurrency mining, the total power of the equipment used for cryptocurrency production is incomparably higher than that of other equipment. Therefore, the third order harmonics in the neutral conductor can be used as an indicator of cryptocurrency production.

\section{Case Study}

This section includes field measurements done in a low-voltage network, as well as the determination method of the electrical loads formed in computer towers by means of harmonic currents. In these measurements, a harmonic analyzer has been used to show real-time maintenance waveforms and realtime harmonics, perform long-term recording and event sign-up when desired.

First, in a three-phase, four-wire, lowvoltage distribution system, the harmonic currents of two different electrical loads consisting of many computer towers have been measured and then recorded.

In the first group, there are ten computer towers and a server, and these computer towers operate on a common network. Figure 8 shows the currents drawn by the ten computer towers and a server and acronyms should be defined the first time they appear in the text, even after the have already been defined in the abstract. Do not use abbreviations in the title unless they are unavoidable.

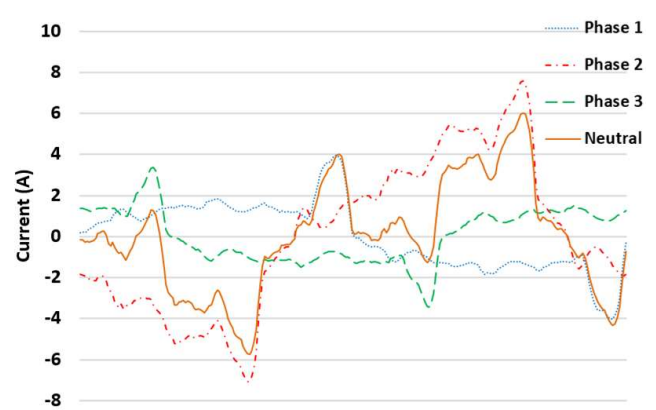

Fig. 8. The currents drawn by ten computer towers and a server

Examining Figure 8, the current is observed to flow over the neutral line. This neutral current is due to the fact that the phases are unbalanced and the loads draw harmonic current. To obtain the harmonic characteristic of a facility, the harmonic spectra of the current flowing over the phases and neutral should be examined. Figure 9 shows the harmonic spectra of phase and neutral currents.

When the harmonic spectra of the phases shown in Figure 9 are examined, it is seen that the system draws high harmonic current, but there is no significant characteristic for the harmonics on the phases that can be observed. Examining the harmonic spectrum of the neutral current, it is observed that the third order harmonics indicated in red are significantly dominant compared to the other harmonics. In addition, depending on whether the load is unbalanced, the basic component current flows on the neutral. The amplitude of the third order harmonics is greater than that of the basic component flowing on the neutral. This shows the extent to which third order harmonics caused by the computer's electrical loads are dominant on the neutral line. 


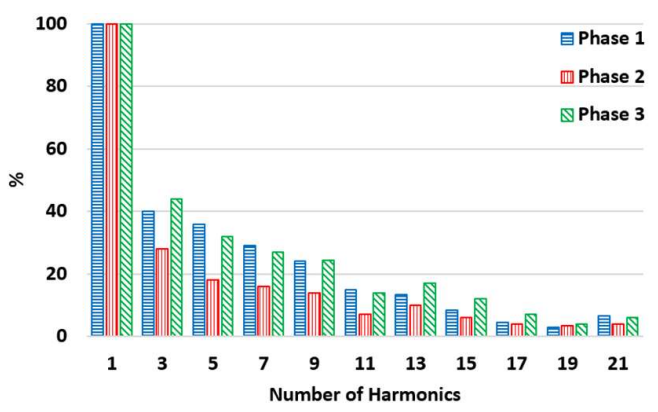

(a)

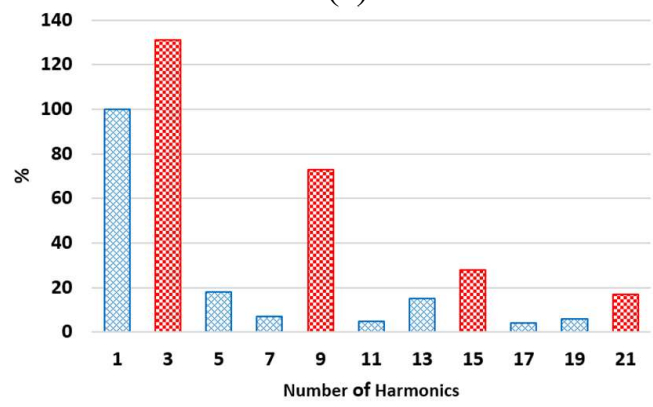

(b)

Fig. 9. (a) Harmonic spectra of phase currents,

(b) Harmonic spectra of the neutral current

In the second group, there are forty computer towers and a server, and these computer towers operate in common network. Figure 10 shows the currents drawn by forty computer towers and a server.

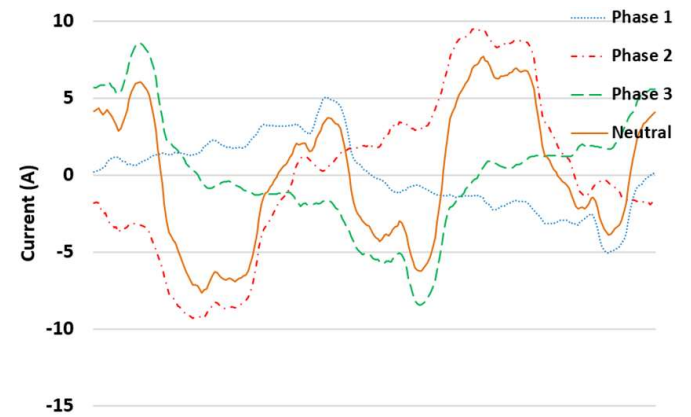

Fig. 10. The currents drawn by forty computer towers and a server

Similar to the first analysis, the harmonic spectrum of the current flowing over the phases and neutral monitored to determine the harmonic characteristic. Figure 11 shows the harmonic spectra of phase and neutral currents.

It is observed in Figure 11 that the third order harmonics dominate the others, which is similar to the first examination. However, when the magnitude of the third harmonic is compared with that of the simple harmonic, the domination of the third harmonic compared to the simple harmonic is much higher in comparison to the first analysis. The main reason for this is the increased number of computer towers in the system. As the number of computer towers connected to the system increases, the third order harmonics become more apparent and even more dominant than the basic component value.

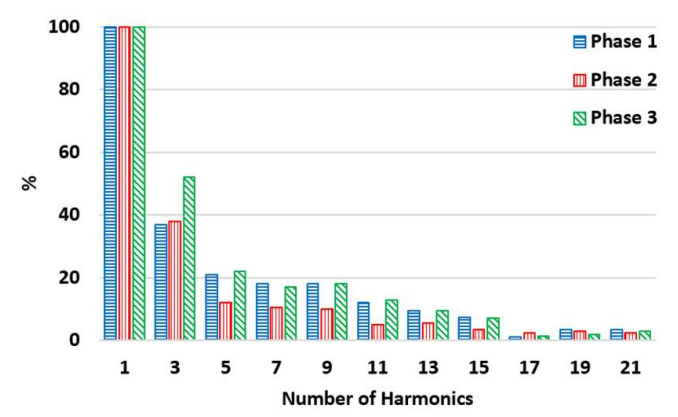

(a)

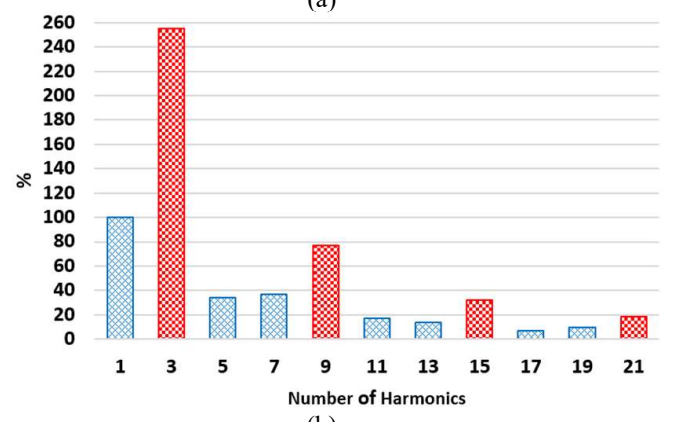

(b)

Fig. 11. (a) Harmonic spectra of phase currents, (b) Harmonic spectra of the neutral current

As a result of analyzing the measurements made on two different groups of computers, it has been proven that the computer's electrical loads were very dominant on the neutral, forming the third order harmonics. Because of the large number of computers present in cryptocurrency centers, cryptocurrency production facilities will generate currents dominated by the third order harmonics on the neutral line.

Electricity distribution companies with many consumers see that consumers where high third order harmonic currents are observed in lines or in distribution transformers are likely to have a cryptocurrency production facility. Due to this strong suspicion, based on the data, a detailed examination can be made at the facility by rapidly obtaining legal permission. As a result of this investigation, if there is 
illegal use of electricity, or the production of illicit cryptocurrencies, the necessary criminal actions can be taken.

The presence of the third order harmonics on the neutral conductor of a facility does not always indicate that it has an computer load, but considering the electrical load of the entire facility, high numbers of third order harmonics on the neutral conductor are encountered in data center or cryptocurrency mining farms.

\section{Conclusion}

Each electrical device has a unique electrical noise and harmonic current characteristic. In this study, an innovative approach has been explained so that it is possible with this approach to accurately detect suspicious data by examining the unique noise and harmonic characteristics of illicit cryptocurrency mining farms. Electricity distribution companies have various problems with detecting suspicious activity, such as the inability to access private properties and the lengthy legal procedures involved in identifying cryptocurrency production facilities using traditional methods. Furthermore, the production of illicit cryptocurrencies in regions with high loss/leakage electricity rates is another major challenge in identifying these facilities. By performing the suggested measurement, it is possible to detect illegal cryptocurrency production centers by obtaining the characteristics of the noise and current harmonic spectra. However, this measurement cannot determine with $100 \%$ accuracy that a facility produces illegal cryptocurrencies. Accordingly, electricity distribution companies should carry out a risk assessment using specific noise and harmonic characteristics. As a result of that risk assessment, the necessary legal permissions should be obtained to inspect the high-risk facilities. The process of obtaining legal permission, which is a lengthy procedure, is therefore applied only for the high-risk facilities, not every facility. As a result, the number of facilities to be examined is reduced, the process can be accelerated and the efficiency is increased.

\section{Acknowledgements}

The author would like to thank Research Assistant Burak Dindar who have been involved in the English-language translation before submitting my manuscript.

\section{References}

[1] S. Adhami, G. Giudici, and S. Martinazzi, "Why do businesses go crypto? An empirical analysis of initial coin offerings," J. Econ. Bus., vol. 100, no. March, pp. 64-75, 2018. https://doi.org/10.1016/j.jeconbus.2018.04.001

[2] A. Gervais, G. O. Karame, V. Capkun, and S. Capkun, "Is Bitcoin a Decentralized Currency?," IEEE Secur. Priv., vol. 12, no. 3, pp. 54-60, 2014. https://doi.org/10.1109/MSP.2014.49

[3] J. Yli-Huumo, D. Ko, S. Choi, S. Park, and K. Smolander, "Where Is Current Research on Blockchain Technology?-A Systematic Review," PLoS One, vol. 11, no. 10, p. e0163477, 2016. https://doi.org/10.1371/journal.pone.0163477

[4] K. Christidis and M. Devetsikiotis, "Blockchains and Smart Contracts for the Internet of Things," IEEE Access, vol. 4, pp. 2292-2303,

https://doi.org/10.1109/ACCESS.2016.2566339

[5] H. Vranken, "Sustainability of bitcoin and blockchains," Current Opinion in Environmental Sustainability. vol. 28, pp. 1-9, 2017. https://doi.org/10.1016/j.cosust.2017.04.011

[6] Digiconomist, "Bitcoin Energy Consumption Index," digiconomist.net, Jan. 2019. [Online]. Available: https://digiconomist.net/bitcoin-energy-consumption. [Accessed: Apr. 5, 2019].

[7] J. Truby, "Decarbonizing Bitcoin: Law and policy choices for reducing the energy consumption of Blockchain technologies and digital currencies," Energy Res. Soc. Sci., vol. 44, no. February, pp. 2018. https://doi.org/10.1016/j.erss.2018.06.009.

[8] S. Nakamoto, "Bitcoin: A Peer-to-Peer Electronic cash system," Bitcoin, 2008.

[9] B. Maurer, T. C. Nelms, and L. Swartz, "'When perhaps the real problem is money itself!': The practical materiality of Bitcoin," Soc. Semiot., vol. 23, no. 2, pp. 261-277, 2013. https://doi.org/10.1080/10350330.2013.777594

[10] G. Milunovich, "Cryptocurrencies, Mainstream Asset Classes and Risk Factors - A Study of Connectedness," The Australian Economic Review, vol. 51, no. 4, pp. 551-563, 2018. https://doi.org/10.1111/1467-8462.12303

[11] A. Hayes, "The Decision to Produce Altcoins: Miners' Arbitrage in Cryptocurrency Markets," Ssrn, 2015. https://doi.org/10.2139/ssrn.2579448

[12] B. U. Tüfek, "Electronic payment tools and approach of the future crypto currency," M. S. thesis, Bahçeşehir University, Istanbul, 2017.

[13] Coinmarketcap, "Top 100 Cryptocurrencies by Market Capitalization," coinmarketcap.com, Jan. 2019. [Online]. Available: https://coinmarketcap.com. [Accessed: Apr. 5, 2019].

[14] Statista, "Bitcoin price index," www.statista.com, Jan. 2019. [Online]. Available: https://www.statista.com/statistics/654937/bitcoin-priceindex-quaterly-data. [Accessed: Apr. 5, 2019].

[15] S. Chow and M. E. Peck, "The bitcoin mines of China," IEEE Spectr., vol. 54, no. 10, pp. 46-53, 2017. https://doi.org/10.1109/MSPEC.2017.8048840

[16] K. J. O'Dwyer and D. Malone, "Bitcoin Mining and its Energy Footprint," 25th IET Irish Signals Syst. Conf. 20142014 China-irel. Int. Conf. Inf. Communities Technol. (ISSC 2014/CIICT 2014), pp. 280-285, 2014 https://doi.org/10.1049/cp.2014.0699

[17] C. Malmo, "One Bitcoin Transaction Consumes As Much Energy As Your House Uses in a Week," motherboard.vice.com, Nov. 1, 2017. [Online]. Available: https://motherboard.vice.com/en_us/article/ywbbpm/bitcoinmining-electricity-consumption-ethereum-energy-climatechange. [Accessed: Apr. 5, 2019].

[18] Y. Liu, X. Chen, L. Zhang, C. Tang, and H. Kang, "An intelligent strategy to gain profit for bitcoin mining pools," Proc. - 2017 10th Int. Symp. Comput. Intell. Des. Isc. 2017, vol. 2, $\quad$ pp. $427-430, \quad 2018$. https://doi.org/10.1109/ISCID.2017.184 
[19] K. Choo, R. M. Galante, and M. M. Ohadi, "Energy consumption analysis of a medium-size primary data center in an academic campus," Energy Build., vol. 76, pp. 414-421, 2014. https://doi.org/10.1016/j.enbuild.2014.02.042

[20] H. Rong, H. Zhang, S. Xiao, C. Li, and C. Hu, "Optimizing energy consumption for data centers," Renew. Sustain. Energy Rev., vol. 58, pp. 674-691, 2016. https://doi.org/10.1016/j.rser.2015.12.283

[21] Elitefixtures, "Bitcoin Mining Costs Throughout the World," www.elitefixtures.com, Feb. 26, 2018. [Online]. Available: https://www.elitefixtures.com/blog/post/2683/bitcoin-miningcosts-by-country. [Accessed: Apr. 5, 2019].

[22] J. Li, N. Li, J. Peng, H. Cui, and Z. Wu, "Energy consumption of cryptocurrency mining: A study of electricity consumption in mining cryptocurrencies," Energy, vol. 168, pp. 160-168, 2018. https://doi.org/10.1016/j.energy.2018.11.046

[23] S. Kais and M. B. Mbarek, "Dynamic relationship between $\mathrm{CO} 2$ emissions, energy consumption and economic growth in three North African countries," International Journal of Sustainable Energy, vol. 36, no. 9, pp. 840-854, 2017. https://doi.org/10.1080/14786451.2015.1102910

[24] M. Z. Nain, W. Ahmad and B. Kamaiah, "Economic growth, energy consumption and $\mathrm{CO} 2$ emissions in India: a disaggregated causal analysis," International Journal of Sustainable Energy, vol. 36, no. 8, pp. 807-824, 2017. https://doi.org/10.1080/14786451.2015.1109512

[25] Paris Agreement, "Convention on Climate Change: Climate Agreement of Paris.," United Nations, Tech. Report. 2015.

[26] Kyoto Protocol, "On Accounting of Emissions and Assigned Amount," United Nations Framework Convention on Climate Change, Tech. Report. 2016.

[27] O. Ç. Deniz, "High electricity consumption gave information against Chinese miner," kriptoparahaber.com, Jun. 23, 2018. [Online]. Available: https://kriptoparahaber.com/asirielektrik-tuketimi-ele-verdi.html. [Accessed: Apr. 5, 2019].

[28] J. Mollen, "Meet the daring detectives sniffing out boobytrapped Bitcoin mines," thenextweb.com, Jul. 30, 2018. [Online]. Available: https://thenextweb.com/iotlab/2018/07/30/bitcoin-mines-fraud-electricity-theft. [Accessed: Apr. 5, 2019].

[29] BBC News, "Russian nuclear scientists arrested for 'Bitcoin mining plot'," www.bbc.com, Feb. 9, 2018. [Online]. Available: https:/www.bbc.com/news/world-europe43003740. [Accessed: Apr. 5, 2019].

[30] Takvim, "Bitcoin miners focus on the Southeast," www.takvim.com.tr, Dec. 26, 2017. [Online]. Available: https:/www.takvim.com.tr/teknoloji/2017/12/26/bitcoinmadencileri-guneydoguyu-gozlerine-kestirdi. [Accessed: Apr. 5, 2019].

[31] IHA, "27.5 million Turkish Liras investments are destroyed for illegal electricity," www.haberturk.com, Nov. 20, 2018. [Online]. Available: https://www.haberturk.com/diyarbakirhaberleri/64831711-kacak-elektrik-icin-27-5-milyon-liralikyatirim-tahrip-ediliyor. [Accessed: Apr. 5, 2019].

[32] R. Jiang, R. Lu, Y. Wang, J. Luo, C. Shen, and X. Shen, "Energy-theft detection issues for advanced metering infrastructure in smart grid," Tsinghua Sci. Technol., vol. 19, no. $2, \quad$ pp. $105-120, \quad 2014$. https://doi.org/10.1109/TST.2014.6787363

[33] S. Güzelgöz, H. B. Çelebi, T. Güzel, H. Arslan, and M. K. Mihçak, "Time frequency analysis of noise generated by electrical loads in PLC," ICT 20102010 17th Int. Conf. Telecommun., $\quad$ pp. $864-871, \quad 2010$. https://doi.org/10.1109/ICTEL.2010.5478758

[34] A. J. Collin, C. E. Cresswell, and S. Ž. Djokić, "Harmonic cancellation of modern switch-mode power supply load," ICHQP 2010 - 14th Int. Conf. Harmon. Qual. Power, 2010. https://doi.org/10.1109/ICHQP.2010.5625422

[35] B. Singh, S. Singh, A. Chandra, and K. Al-Haddad, "Comprehensive study of single-phase AC-DC power factor corrected converters with high-frequency isolation," IEEE Trans. Ind. Informatics, vol. 7, no. 4, pp. 540-556, 2011. https://doi.org/10.1109/TII.2011.2166798

[36] S. Singh, B. Singh, G. Bhuvaneswari, and V. Bist, "Improved Power Quality Switched-Mode Power Supply Using BuckBoost Converter," IEEE Trans. Ind. Appl., vol. 52, no. 6, pp. 5194-5202, 2016. https://doi.org/10.1109/TIA.2016.2600675

[37] IEEE Power and Energy Society, "IEEE Recommended Practice and Requirements for Harmonic Control in Electric Power Systems IEEE Power and Energy Society," IEEE Stand. 519-2014, vol. 2014, 2014.

[38] Standards Council of Canada, "Electromagnetic compatibility (EMC) - Part 3-6: Limits - Assessment of emission limits for the connection of distorting installations to $\mathrm{MV}, \mathrm{HV}$ and $\mathrm{EHV}$ power systems," CAN/CSA Stand. C61000-3-6-04, 2014.

[39] International Electrotechnical Commission, "Electromagnetic compatibility (EMC) Part 3-2: Limits Limits for harmonic current emissions (equipment input current=16 A per phase," IEC Stand. 1000-3, 2018.

[40] A. B. Nassif and Y. Wang, "Power Quality Characteristics and Electromagnetic Compatibility of Modern Data Centres," 2018 IEEE Can. Conf. Electr. Comput. Eng., pp. 1-4, 2018. https://doi.org/10.1109/CCECE.2018.8447607. 